\title{
Disección espontánea de arteria vertebral en la consulta otorrinolaringológica: Reporte de caso
}

\author{
Spontaneous dissection of the vertebral artery in \\ otorhinolaryngologic consultation: Case report
}

\author{
Marcela Castillo $\mathrm{F}^{1}$, Andrés Finkelstein $\mathrm{K}^{2}$, Jorge Caro $\mathrm{L}^{3}$.
}

\begin{abstract}
RESUMEN
La disección espontánea de arteria vertebral es una causa frecuente de accidente vascular encefálico en población joven.

A continuación informamos el caso de un paciente masculino de 42 años, quien se presenta en la consulta otorrinolaringológica con un cuadro de instalación aguda de cefalea asociada a déficit de pares craneanos e inestabilidad de la marcha, el cual fue interpretado en un servicio de urgencia como un síndrome vertiginoso periférico, luego de una tomografía computada de cerebro sin contraste normal. Se procede a solicitar angiorresonancia, diagnosticándose disección espontánea de arteria vertebral derecha, motivo por el cual es hospitalizado y manejado con anticoagulación sistémica con buena evolución.
\end{abstract}

Palabras clave: Disección arteria vertebral, accidente vascular encefálico.

\section{SUMMARY}

Spontaneous dissection of the vertebral artery is a frequent cause of encephalic vascular accident in young population. Below we report the case of a 42 year old male patient who attends the otorhinolaryngological clinic with a picture of acute installation of migraine associated to deficit of cranial pairs and instability in walk, that was interpreted at an emergency ward as a peripheral vertiginous syndrome, after a computed tomography of the brain without normal contrast. An angioresonance is requested, diagnosing spontaneous dissection of the right side vertebral artery, for which reason he is hospitalized and treated with systemic anticoagulation, with positive evolution

Key words: Dissection of the vertebral artery, encephalic vascular accident.

\footnotetext{
${ }^{1}$ Médico Hospital Dr. Sótero del Río.

${ }^{2}$ Médico Hospital Cínico Pontificia Universidad Católica de Chile.

${ }^{3}$ Médico Unidad Asociada Otorrinolaringología, Pontificia Universidad Católica de Chile.
} 


\section{INTRODUCCIÓN}

La disección espontánea de arteria vertebral (DEAV) es una patología descrita clásicamente como causa poco frecuente de accidente vascular encefálico, siendo diagnosticada post mortem en la gran mayoría de los casos. Desde fines de la década de los 70, debido a los avances en tecnología diagnóstica, se ha podido reconocer esta entidad en un número creciente de pacientes, con un importante aumento de los casos reportados en la literatura. Con ello, se ha podido instaurar un manejo clínico precoz y con mejores resultados. A pesar de no ser una enfermedad que comúnmente sea manejada por el otorrinolaringólogo, su sintomatología hace que con relativa frecuencia sean estos especialistas los que reciban por primera vez a los enfermos. Lo anterior, obliga a tener un alto nivel de sospecha, teniendo en cuenta esta patología como parte del diagnóstico diferencial.

\section{CASO CLÍNICO}

Se trata de un paciente de 42 años de edad, visto en consultorio externo de ORL, sexo masculino, con antecedente de insuficiencia renal crónica en hemodiálisis. Consulta por un cuadro de instalación brusca que comenzó hace 48 horas, caracterizado por disfonía, disfagia, inestabilidad en la marcha, cefalea y vómitos. Había sido evaluado 3 veces en un Servicio de Urgencia, en donde se le habría realizado un scanner cerebral sin contraste, informado como normal. Es enviado a control otorrinolaringológico por un neurocirujano de urgencia, con diagnóstico de síndrome vertiginoso.

Al ingreso a la consulta, se observa un paciente en silla de ruedas que no logra ponerse de pie, consciente y orientado, con disfonía, diplofonía y tos. No refiere hipoacusia ni tinnitus. Al examen físico destaca una asimetría del velo del paladar, con hipoestesia del hemicuerpo izquierdo y una marcha alterada con lateropulsiones a izquierda. No presenta nistagmus espontáneo. Se le realiza una nasofibroscopía que revela una parálisis de cuerda vocal derecha. Ante esto se solicita evaluación urgente por neurólogo con diagnóstico presuntivo de infarto troncoencefálico en evolución, por lo que se deriva para hospitalización. Se le realiza una angiorresonancia nuclear magnética que muestra infarto de tronco secundario a una disección de arteria vertebral (Figuras 1 y 2), lo

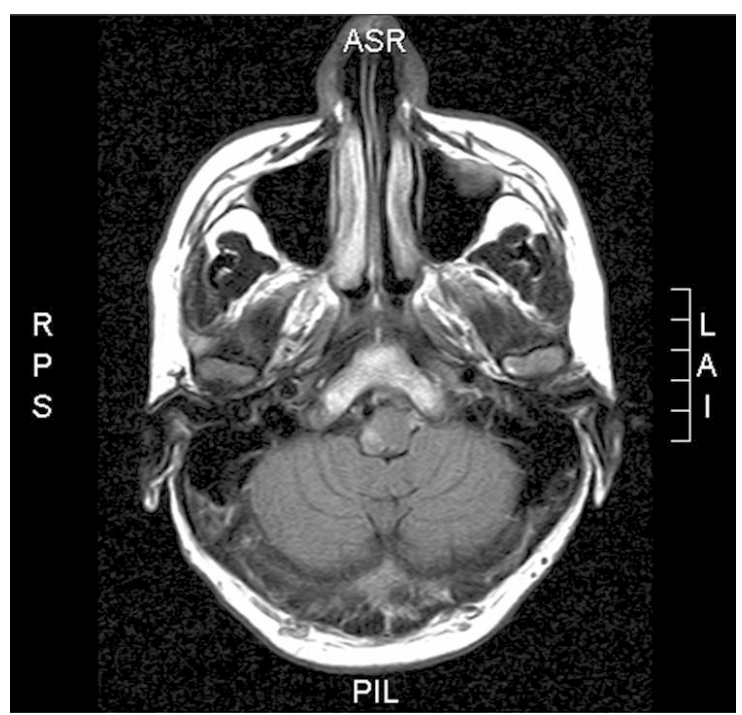

Figura 1. Resonancia nuclear magnética de encéfalo. 


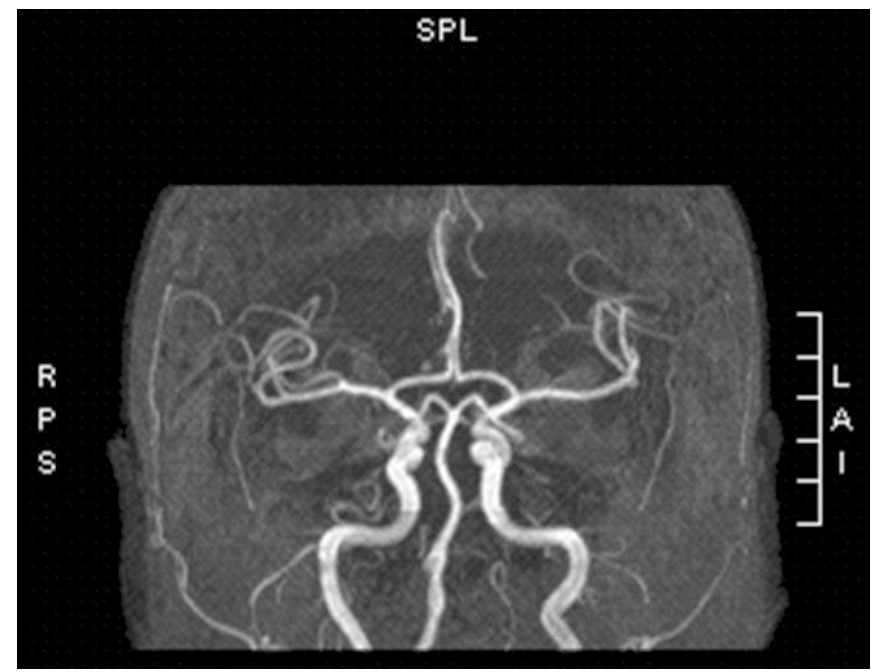

Figura 2. Angiorresonancia de territorio vertebrobasilar.

cual fue luego confirmado por angiografía convencional (Figura 3). Se inicia manejo con tratamiento anticoagulante sistémico, con lo cual se observa recuperación progresiva de las funciones neurológicas en las semanas posteriores.

\section{DISCUSIÓN}

No existen datos nacionales acerca de la magnitud de la DEAV en nuestro país, pero en la literatura norteamericana se estima una incidencia anual de

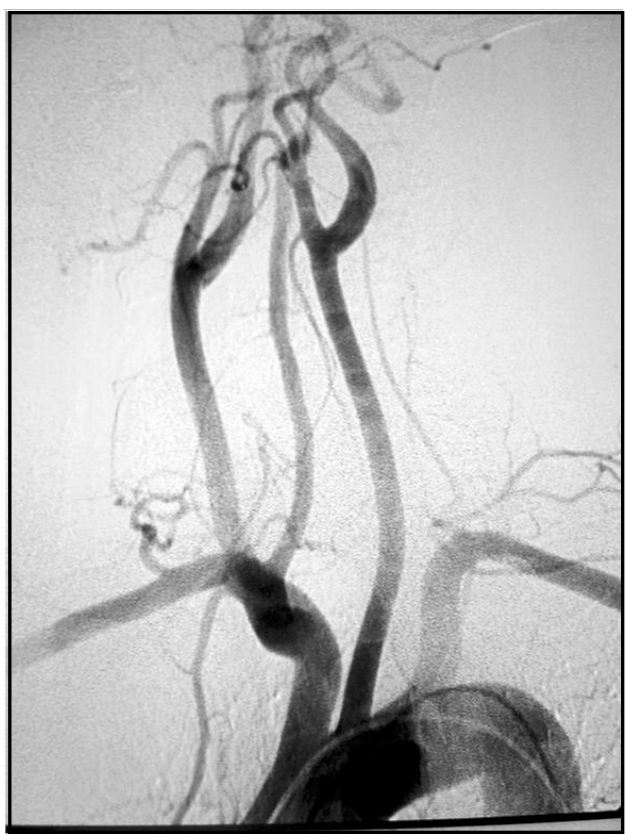

Figura 3. Angiografía de territorio vertebrobasilar. 
1-1,5 casos por cada 100.000 habitantes, con edad promedio de 40 años. A pesar de no corresponder a más del $2 \%$ de las causas de accidente vascular encefálico isquémico, cobra gran importancia en la población adolescente y edad media, explicando el $10 \%-25 \%$ de estos sucesos. No parece haber mayor diferencia en la incidencia entre ambos sexos, pero se sabe que las mujeres que lo presentan lo hacen en promedio 5 años antes que los hombres ${ }^{1}$. Estos datos epidemiológicos concuerdan plenamente con lo presentado por el paciente, perteneciendo al grupo etario en el cual se observa con mayor frecuencia esta patología.

Se cree que en la patogenia de las DEAV intervienen alteraciones genéticas que condicionan defectos estructurales intrínsecos de la pared de los vasos sanguíneos, siendo esta arteriopatía desconocida en la gran mayoría de los pacientes. Dentro de las enfermedades del tejido conectivo que comúnmente se asocian a la DEAV se encuentra el síndrome de Ellers-Danlos tipo IV, síndrome de Marfán, enfermedad de riñones poliquísticos autonómica dominante y la osteogénesis imperfecta tipo I, siendo reconocidas en un $1 \%-5 \%$ de los pacientes. Además hay otro $5 \%$ de pacientes que presentan historia familiar de disecciones arteriales espontáneas o alteraciones sugerentes de otras enfermedades del tejido conectivo. Estudios ultraestructurales han revelado que un $66 \%$ de los pacientes con DEAV presentan anormalidades de los componentes del tejido conectivo dérmico, pero no han podido demostrar alteraciones en genes clave como procolágeno III, procolágeno $\mathrm{Vy}$ tropoelastina Se han reconocido también una serie de factores ambientales que podrían condicionar la ocurrencia de DEAV. Eemplos de éstos son hiperextensiones o rotaciones cervicales al practicar yoga, pintar, toser, estornudar o al recibir RCP. Además de esto, diversos estudios han sugerido que maniobras quiroprácticas pudieran desencadenar esta patología, habiendo publicaciones que estiman que se produce un accidente vascular encefálico por cada 20.000 manipulaciones espinales. Sin embargo, este dato es discutible dado que la cervicalgia que lleva al paciente a recibir este tipo de tratamiento muchas veces ha sido originada por la DEAV misma. Además de estos factores mecánicos, se estudia un rol por parte de microorganismos como factor de riesgo para presentar este cuadro, siendo el más estudiado la Chalmydia pneumoniae, lo cual es sospechado por la variación estacional en la incidencia de las DEAV. Otros factores de riesgo cardiovasculares clásicos como HTA, tabaco, uso de anticonceptivos, etc, no han sido evaluados en forma sistemática, pero el hallazgo de ateroesclerois en la disección es poco frecuente ${ }^{1-4}$. En consistencia con lo señalado en la literatura, este paciente no tenía ninguna de las patologías genéticas ni condiciones ambientales que aumentan el riesgo para la DEAV, siendo probablemente una arteriopatía desconocida. Probablemente el daño vascular secundario a su nefropatía pudiera contribuir en un rol etiopatogénico.

Las manifestaciones clínicas de las DEAV se pueden dividir en locales e isquémicas. Las manifestaciones locales incluyen cervicalgia y cefalea. La cervicalgia ocurre en un $50 \%$ de los pacientes, comenzando en promedio 2 semanas antes de que se produzcan manifestaciones isquémicas, pudiendo ser tanto unilateral como bilateral. Su asociación a braquialgia o hipoestesia de la extremidad superior ipsilateral es poco frecuente. La cefalea ocurre en un $66 \%$ de los pacientes con DEAV, siendo con mayor frecuencia occipital, de carácter pulsátil, o bien, constante y punzante. En promedio, el período entre el inicio de la cefalea y los síntomas neurológicos es de 15 horas. Sólo un $50 \%$ de los pacientes reconoce la cefalea como distinta a episodios previos, pero es muy infrecuente que un paciente jaquecoso no la reconozca como un cuadro diferente.

Los síntomas isquémicos ocurren en más del 90\% de los pacientes con DEAV, y derivan del compromiso del tronco encefálico, parte lateral de la médula (síndrome de Wallemberg), tálamo, y tanto hemisferios cerebelosos como cerebrales. De esto se desprende que los síntomas más frecuentes son la disestesia facial ipsilateral, disatria, disfonía, hipoestesia ipsilateral, pérdida del gusto ipsilateral, vértigo (nistagmus), náuseas, vómitos, diplopia, disfagia, ataxia y el síndrome de Claude 
Bernard Horner. Con menor frecuencia se puede presentar paresia o hipoestesia contralateral. $\mathrm{日}$ exceso de confianza en métodos de imágenes con sensibilidad insuficiente en desmedro de la adecuada evaluación clínica, fue lo que generó el error diagnóstico en el servicio de urgencia al cual acudió inicialmente este paciente ${ }^{1-3}$. Para plantear un síndrome vertiginoso periférico, no debe haber focalizaciones neurológicas. Ante la presencia evidente de compromiso de pares craneanos y otros déficits neurológicos, una patología del sistema nervioso central debe ser descartada en forma activa con las imágenes adecuadas, para así evitar el retraso en el diagnóstico de una enfermedad potencialmente grave.

La angiografía convencional ha sido clásicamente el Gold Standard para el diagnóstico de las DEAV. Este examen permite ver tanto las lesiones estenóticas como las dilataciones pseudoaneurismáticas, ambas más frecuentes en el segmento distal de la arteria, a nivel de C1-C2. Un lugar menos frecuente de disección es la porción proximal de la arteria, justo antes de su entrada al foramen intervertebral. Este examen muestra que hasta un $10 \%$ de las DEAV se extienden en forma intracranena.

Las técnicas angiográficas con resonancia nuclear magnética han ido reemplazando a la angiografía convencional como método diagnóstico de elección, aportando un rendimiento similar con las ventajas de ser menos invasiva, mostrar directamente el hematoma intramural, y permitir un diagnóstico preciso en los casos en que la disección no se asocia a alteraciones luminales o bien al observar oclusiones de carácter inespecífico. Así se puede ver como es poco probable que la TAC sin contraste pudiera haber sido de utilidad en este caso, siendo la angiorresonancia el examen de elección ${ }^{1-3,5}$. Ante la falta de disponibilidad de este examen en el sistema público de salud, la conducta adecuada hubiera sido la hospitalización del paciente, y la realización de una angiografía convencional, o bien, haber solicitado a los familiares apoyo económico para su realización en el sistema privado. $\mathrm{日}$ rol de la ultrasonografía es bastante limitado, reservándose para la evaluación inicial de los pacientes en que se sospecha una lesión vascular del cuello, con el uso del doppler y la ecografía transcraneana ${ }^{6}$.

Al igual que lo realizado en el paciente en cuestión, la base de la terapia de la DEAV es la anticoagulación sistémica, exceptuando a los pacientes que tienen al guna contraindicación, o bien, los que tienen extensión intracraneana de la disección. $日$ nivel sugerido es de un INR entre 2 y 3 por un período de 3 a 6 meses. A pesar de que no hay estudios clínicos controlados de calidad que evalúen esta conducta, hay evidencia indirecta de su probable utilidad, dado que el $90 \%$ de los accidentes vasculares encefálicos secundarios a las DEAV son por fenómenos tromboembólicos y no por disminuciones del flujo sanguíneo secundarias a ésta ${ }^{1-3}$.

Afortunadamente, la evolución clínica del paciente fue bastante favorable, algo que es consistente con lo descrito en la literatura, con una mortalidad reportada inferior al 5\%, y una recuperación a un nivel funcional aceptable en un $75 \%$ de los casos. La cefalea se resuelve en el $90 \%$ de los pacientes antes de la primera semana de tratamiento, pero hay casos en que puede prolongarse por años. La incidencia de una nueva DEAV en un paciente que ya sufrió uno es de $2 \%$ durante el primer mes, siendo luego de sólo $1 \%$ al año. Sin embargo el aumento del riesgo con respecto a la población general se mantiene por una década o más ${ }^{1}$.

\section{CONCLUSIONES}

A pesar de no ser una causa frecuente de accidente vascular encefálico, las DEAV tienen una importancia relativamente alta en la población joven, lo que obliga a tener un alto índice de sospecha para su diagnóstico. Dada la sintomatología que presentan, no es infrecuente que sea el otorrinolaringólogo el primer especialista que enfrente a estos pacientes, por lo que debe estar preparado para reconocer los elementos de la historia y examen físico que orienten a un cuadro de origen central y potencialmente grave como el presentado en este artículo. 


\section{BIBLIOGRAFÍA}

1. SAVITZ SI, CAPLAN LR. Vertebrobasilar disease. NEngl J Med 2005;352(25): 2618-26.

2. CAPLAN LR, BIOUSSE V. Cervicocranial arterial dissections. J Neuroophthalmol 2004; 24(4): 299-305.

3. SCHIEVINK WI. Spontaneous dissection of the carotid and vertebral arteries. $N$ Engl $J$ Med 2001; 344(12): 898-906.
4. ERNST E Life-threatening complications of spinal manipulation. Stroke 2001; 32(3): 809-10.

5. JEWELLS V, CASTILLOM. MR angiography of the extracranial circulation. Magn Reson Imaging Cin NAm 2003; 11(4): 585-97, vi.

6. LANDWEUR P, SCHULTEO, VOSHAGE G Ultrasound examination of carotid and vertebral arteries. Eur Radiol 2001; 11(9): 1521-34.

Dirección: Dra. Marcela Castillo Franzoy

Marcoleta 387, Santiago

Fono: 09-8796103

Email: mcastillito@yahoo.comador 364 